\section{Miositis osificante del músculo pterigoideo medial secundaria a enucleación de quiste dentígero: reporte de caso}

\section{Myositis ossificans of the medial pterygoid muscle post dentigerous cyst enucleation: case report}

\begin{abstract}
Resumen
La miositis osificante es una rara entidad caracterizada por depósito de hueso heterotópico en tejidos blandos, siendo su principal ubicación el músculo, se han descrito dos variantes: miositis osificante progresiva y miositis osificante traumatica (MOT). El objetivo de este artículo es reportar el primer caso de MOT diagnosticado en México, en paciente femenina de 11 años de edad, quien posterior a enucleación de quiste dentígero desarrolló limitación progresiva a la apertura oral, dolor y trismus, al examen físico sin palpación de masas o deformidades dentro de la cavidad, con apertura oral de $0 \mathrm{~mm}$; en el estudio tomográfico y de reconstrucción se identifica imagen hiperdensa bien definida compatible con calcificación a nivel del músculo pterigoideo medial. Se llevó a resección de lesión, confirmándose diagnostico por histopatología. Paciente actualmente en vigilancia clínica y apoyo con fisioterapia, sin datos de recurrencia.
\end{abstract}

Palabras clave: Miositis osificante; Músculos pterigoideos; Cirugía; Trismo (fuente: DeCS BIREME).

\begin{abstract}
Myositis ossificans is a rare entity characterized by heterotopic bone deposition in soft tissues, being located mainly in muscle, two variants have been described: progressive myositis ossificans (PMO) and traumatic myositis ossificans (TMO). The objective of this article is to report the first case of TOM diagnosed in Mexico, in an 11-year-old female patient, after enucleation of the dentigerous cyst, developed progressive limitation to the oral opening, pain and trismus, to the physical examination without palpation of mass or deformities within the cavity, with an oral opening of $0 \mathrm{~mm}$; The tomographic and reconstruction study identified a well-defined hyperdense image compatible with calcification at the level of the medial pterygoid muscle. The lesion was resected, confirming the diagnosis by histopathology. Nowadays the patient currently clinical surveillance and physical therapy support, with no recurrence.
\end{abstract}

Keywords: Myositis ossificans; Pterygoid muscles; Surgery; Trismus (source: MeSH NLM).

\section{Caso Clínico}

Fidel Jiménez Zúñiga ${ }^{1, a}$, Daniel Medecigo Costeira ${ }^{2, b}$ Carlos Eduardo Varela Ibáñez ${ }^{2, b}$, José Ernesto Miranda Villasana ${ }^{1, b}$

${ }^{1}$ ISSSTE Hospital Regional General "Ignacio Zaragoza "Ciudad de México, México

${ }^{2}$ Hospital "Niño DIF" Pachuca, México.

a Cirujano Dentista.

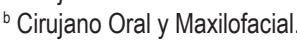

\section{Correspondencia:}

Fidel Jiménez Zúñiga: fideljimenez798@gmail.com Calle 11 Manzana 11 Lote 328 Colonia Belisario Domínguez Secc XV. Código Postal 1408.

ORCID: 0000-0002-1063-0183

\section{Coautores:}

Daniel Medecigo Costeira: dancosterinacmf@gmail.com ORCID: 0000-0001-8674-4243

Carlos Eduardo Varela lbáñez: eduardovarelacmf@gmail.com ORCID: 0000-0001-9352-3481

José Ernesto Miranda Villasana: ernestomirandahrgiz@ gmail.com

ORCID: 0000-0003-2395-6366

\section{Editora:}

Marieta Petkova-Gueorguieva

Universidad Nacional Mayor de San Marcos, Perú.

Conflicto de intereses: no se presentaron conflictos de interés durante la realización de este trabajo.

Fuente de financiamiento: este proyecto fue autofinanciado.

\section{Recibido: 31/03/20}

Aceptado: $19 / 05 / 20$

Publicado: 04/08/20

(C) Los autores. Este artículo es publicado por la revista Odontología Sanmarquina de la Facultad de Odontología, Universidad Nacional Mayor de San Marcos. Este es un artículo de acceso abierto, distribuido bajo los términos de la licencia Creative Commons Atribucion - No Comercia_Compartir Igual 4.0 Internacional. (http://creativecommons.org/licenses/by-nc-sa/4.0/) que permite el uso no comercial, distribución y reproducción en cualquier medio, siempre que la obra original sea debidamente citada. 


\section{Introducción}

La miositis osificante, es una entidad rara caracterizada por la presencia de depósitos óseos ya sea en el músculo o en los tejidos blandos. Suele clasificarse en miositis osificante progresiva (MOP) y miositis osificante traumática (MOT) ${ }^{1,2}$. La primera descripción de esta entidad fue propuesta por Thoma en 1958 como la osificación progresiva de un hematoma intramuscular después de un traumatismo ${ }^{2}$.

La MOP también llamada fibrodisplasia osificante progresiva, se considera una enfermedad autosómica dominante, suele estar asociada con sobreexpresión de los genes que codifican la proteína morfogénica del hueso (BMP4). Es diagnosticada en la niñez o adolescencia, definida por la presencia de osificaciones heterotópicas en diversos tejidos, tales como músculos, fascias, tendones y ligamentos ${ }^{3,4}$. La misma se desarrolla de manera progresiva y asimétrica provocando en ocasiones restricción en el movimiento de ciertas articulaciones lo que genera anquilosis en fases avanzadas 5,6 . Dichos pacientes suelen morir de complicaciones pulmonares, dada la afectación de la musculatura torácica y debido a esto su pronóstico suele ser pobre.

Por otra parte, la miositis osificante traumática (MOT), conocida también como miositis localizada o fibrodisplasia osificante circunscrita ${ }^{7-10}$, es desarrollada a consecuencia de una lesión única o repetida de un músculo, al generar una alteración en el proceso normal de cicatrización provocando acúmulo de tejido óseo que reemplaza el tejido muscular normal ${ }^{11-13}$.

Se desconoce el mecanismo fisiopatológico exacto por el cual se desarrolla esta entidad y se han intentado generar ciertas teorías que pudiesen explicar este fenómeno. En 1924, Carey ${ }^{14}$ enumeró cuatro teorías para el desarrollo de MOT: 1) Desplazamiento de fragmentos óseos en tejidos blandos y hematomas con proliferación posterior; 2) Desprendimiento de fragmentos periósticos en el tejido circundante con proliferación de células osteoprogenitoras; 3 ) migración de células progenitoras del subperiostio a los tejidos blandos circundantes a través de perforaciones periósticas inducidas por el trauma; 4) diferenciación de células extra óseas expuestas a la proteína morfogénica ósea ${ }^{15}$. A pesar de citarse todas estas teorías, en la actualidad se considera que la entidad no puede ser explicada solo aplicando una de ellas y en muchos casos se puede deber a una mezcla de las mismos, sin poderse determinar el detonante en la mayoría. En los últimos años se ha adicionado una nueva teoría propuesta por Kaplan et al ${ }^{15}$, en la cual se demuestra que existe una mutación recurrente en el dominio de activación del receptor de activina (ACVR1) con evidencia de reemplazo de glicina por serina, provocando una alteración en la señalización del BMP lo que puede representarse en una mineralización ectópica en sitios con traumatismos recurrentes ${ }^{15,16}$.

Las manifestaciones clínicas pueden presentarse en dos fases, que se encuentran en concordancia con las manifestaciones radiológicas descritas abajo. La etapa inicial o también llamada de desarrollo, abarca las primeras 12 semanas en donde se presenta dolor localizado en la zona de osificación, el mismo varia de intensidad hasta tornarse permanente y es aquí donde puede aparecer la zona de induración que suele simular una masa. Al tercer mes se detiene el crecimiento de la lesión y el dolor suele mejorar. Por lo que se considera que hay consolidación de la misma y es posible identificar en este punto cambios bioquímicos en los que se destaca la elevación de la velocidad de sedimentación globular y presencia de leucocitosis, datos que son considerados inespecíficos ${ }^{17}$.

En los estudios radiológicos puede identificarse el proceso de formación ósea, encontrándose diferentes hallazgos dependiendo del momento en el que se realice el estudio. La lesión inicial se visualiza como una masa poco definida con opacidad irregular y de aspecto débil ${ }^{18}$. Posteriormente pueden identificarse las calcificaciones en la segunda o tercera semana subsecuente al trauma, formándose en la imagen una zona focal caracterizada por un nido radio lúcido que es rodeado de un halo calcificado, siendo completamente evidente entre la semana 4 a la $6^{19}$. Esta última característica, es clave para el diagnóstico diferencial con neoplasias malignas ya que es señal de que existe corteza intacta alrededor de la masa. La realización de estudios complejos tales como tomografía axial computariza y resonancia magnética ayudan a delimitar la localización extraesquelética, extensión de la lesión, y son utilizadas para hacer una adecuada planeación quirúrgica, dado que ayudan a delimitar la zona y el patrón de mineralización con mayor precisión ${ }^{20,21}$. Debe realizarse después de la tercera semana y suele identificarse un área hiperdensa producida por las calcificaciones que rodea a una lesión central de densidad variable ${ }^{22}$. Dado estos hallazgos no es necesaria la confirmación histopatológica previa a la resección quirúrgica, la cual es el tratamiento de elección.

Debido a lo descrito previamente suele verse en sitios con alto riesgo de traumatismo, por lo que comúnmente es manejado en el servicio de ortopedia, siendo muy rara la localización en cabeza y cuello ${ }^{23,24}$. Por esta razón, el objetivo de este artículo es reportar el primer caso descrito en México de MOT localizado en el músculo pterigoideo medial en una niña.

\section{Reporte del caso}

Paciente de sexo femenino de 11 años de edad, quien se presentó al servicio de cirugía maxilofacial del Hospital Niño DIF, Pachuca (México) refiriendo presencia de lesión quística en ángulo mandibular izquierdo, se realizó radiografía panorámica (Figura 1) en la que se observó un lesión radiolúcida en cuerpo y ángulo mandibular izquierdo compatible con quiste dentígero, por lo que se decidió escisión local de la misma. Previa firma de consentimiento informado por la madre, se programó procedimiento bajo anestesia general balanceada, se abordó de manera intraoral y adicionalmente se infiltró la región retromolar con lidocaína más epinefrina para mayor control, se accedió a la zona de la lesión quística y se realizó enucleación quirúrgica y curetaje. El material 
obtenido fue enviado a revisión de patología cuyo informe histopatológico confirmó como diagnóstico definitivo al quiste dentígero, revelando presencia de epitelio odontogénico y tejido conjuntivo fibroso no queratinizado con escasas células.
En su postquirúrgico a las 4 semanas se presentó con dolor, trismus e incremento progresivo de la limitación a la apertura oral, (Figura 2); al examen extra oral no se observó apertura bucal, sin identificarse masas o adenopatías en el cuello.

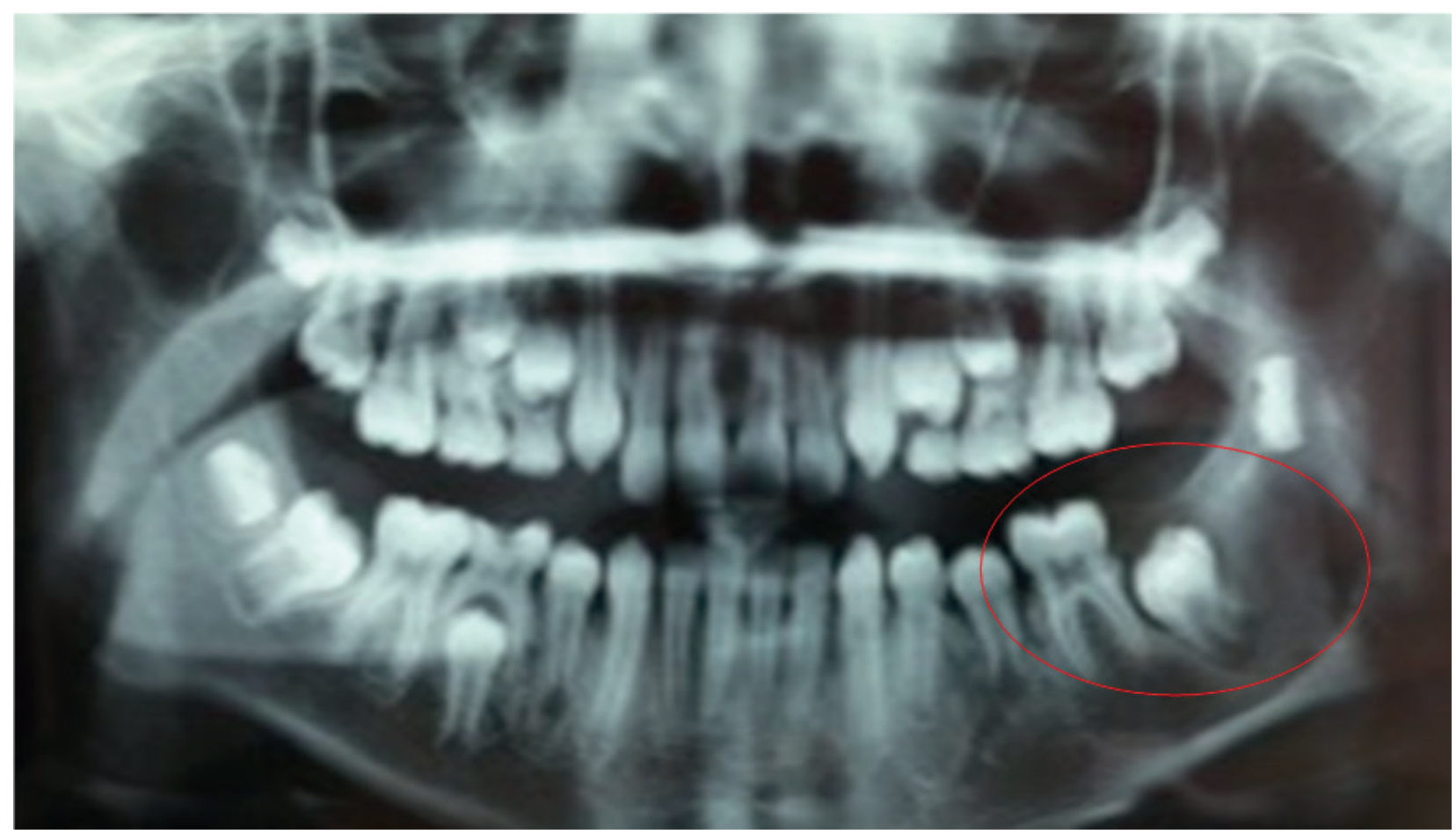

Figura 1. Radiografía panorámica. Evidencia de órgano dentario en rama mandibular izquierda con zona radiolúcida adyacente compatible con quiste dentígero.

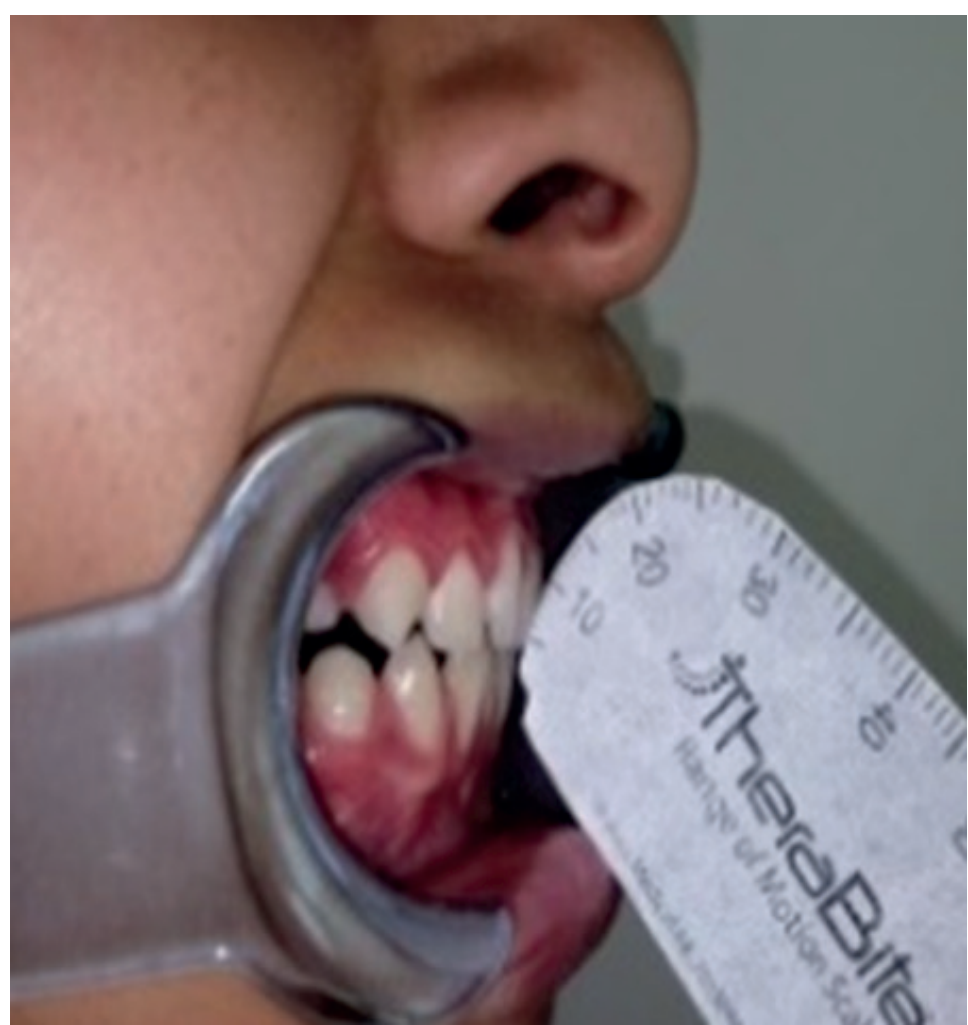

Figura 2. Limitación a la apertura oral. Evaluada con regla de medición milimétrica 
En la tomografía axial con cortes coronales (Figuras 3A y 3B) realizada a las 7 semanas se observó zona hiperdensa bien definida de 2,2 × 2 centímetros a nivel del ángulo mandibular, cara interna compatible con calcificación del musculo pterigoideo medial; complementamos con reconstrucción tridimensional (Figura 4A) que mostró una masa calcificada en la zona de la inserción muscular del pterigoideo interno, se realizó impresión 1:1 con estereolitografía (Figura 4B) para la planeación quirúrgica.
Con estos hallazgos clínicos e imagenológicos descritos, se discutieron como impresiones diagnósticas: miositis osificante traumática, osteoma o condrosarcoma, finalmente decidiendo como primera posibilidad miositis osificante. Por lo que llevamos a resección quirúrgica, realizándose abordaje quirúrgico extra oral submandibular (Figuras 5A y 5B). Posteriormente se realizó corte del mismo con la fresa quirúrgica de baja velocidad $702 \mathrm{~L} \mathrm{y}$ osteotomías con cincel recto hasta desprender la inserción muscular que se encontró calcificado, se continuó con

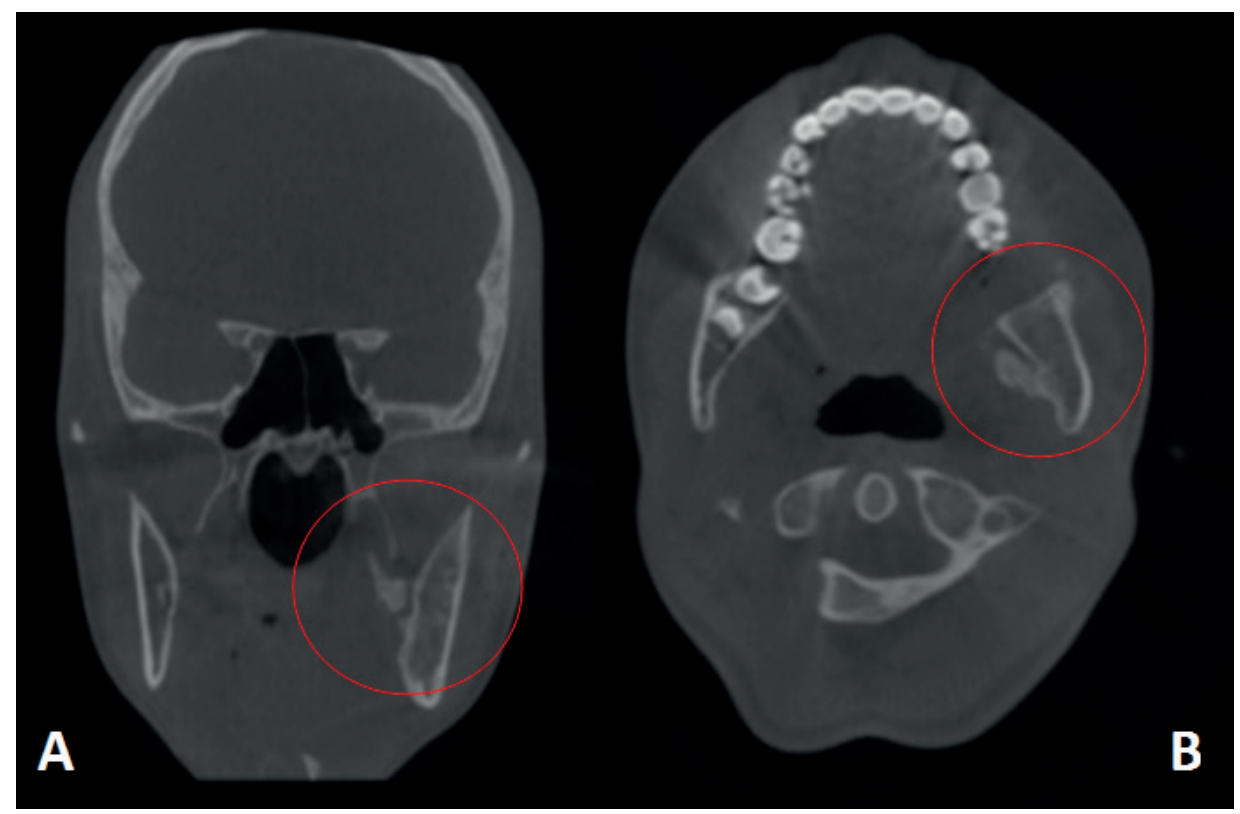

Figura 3. Corte tomográfico A. Coronal B. Axial. Círculo rojo señala zona hiperdensa a nivel del ángulo mandibular, cara interna izquierda
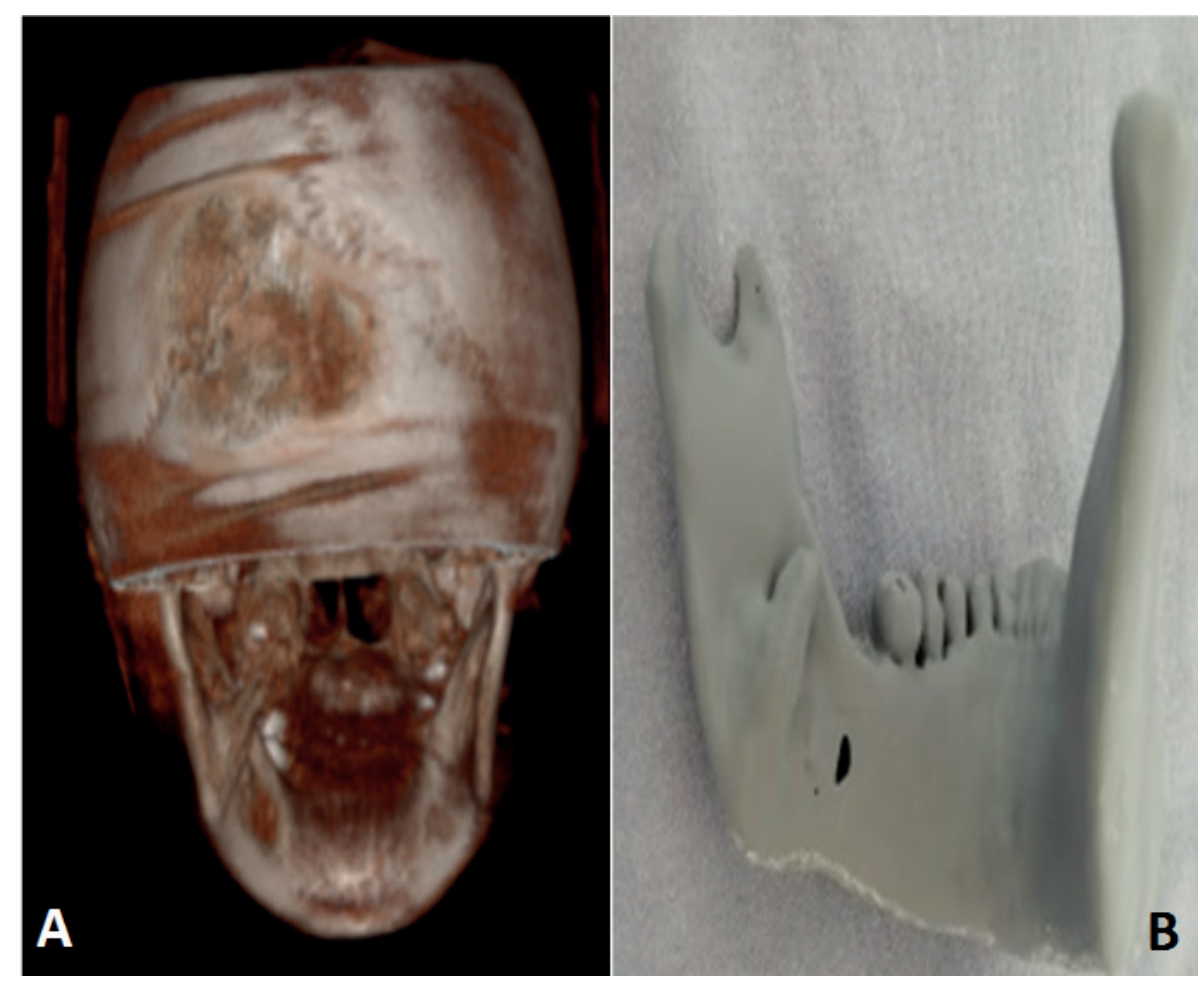

Figura 4. A. Reconstrucción 3D. Masa calcificada en zona de inserción del pterigoideo medial izquierdo B. Esterolitografía 
abordaje intraoral observando una apertura de $35 \mathrm{~mm}$ y posterior abordaje mucogingival (Figuras $5 \mathrm{C}$ y $5 \mathrm{D}$ ) a nivel de órgano dentario incisivo central superior izquierdo y premolar del mismo cuadrante realizando una disección por planos hasta llegar al tejido óseo y con cincel curvo realizar disyunción pterigoidea, finalmente retirando los fragmentos óseos por ambos abordajes. Fue realizada revisión postquirúrgica mediata con tomografía computariza coronal y nueva reconstrucción tridimensional (Figuras 6A y 6B), sin evidencia de fragmentos óseos.

El examen histopatológico informó presencia de tejido óseo vital medular y trabecular rodeado de estroma fibroso (Figura 7).

Dos semanas posteriores a procedimiento quirúrgico se realizó revisión clínica de la apertura oral (Figura 8) y se coloca aparato corrector como parte de fisioterapia para evitar recurrencias. Después de 6 meses de seguimiento no se observaron datos de recidiva.

\section{Discusión}

La MOT, término criticado en muchas instancias, debido a que contrario al nombre no existe inflamación muscular y en muchas ocasiones suele estar ausente en la lesión, es una condición benigna y auto limitada. Se ha descrito principalmente en relación con articulaciones grandes debido a traumas repetidos en estas zonas. Los reportes de involucro de la región maxilofacial son escasos, siendo el masetero el músculo más comúnmente afectado seguido del temporal y en raras ocasiones el pterigoideo medial o lateral. Hanisch et al ${ }^{22}$, publicó una revisión sistemática y reporte de 21 casos de compromiso del músculo pterigoideo medial a nivel mundial, siendo esta la mayor serie informada, sin embargo, no incluye ningún paciente de la región Latinoamérica.

Hasta el momento el único factor de riesgo comprobado ha sido el trauma reiterativo durante la fase de

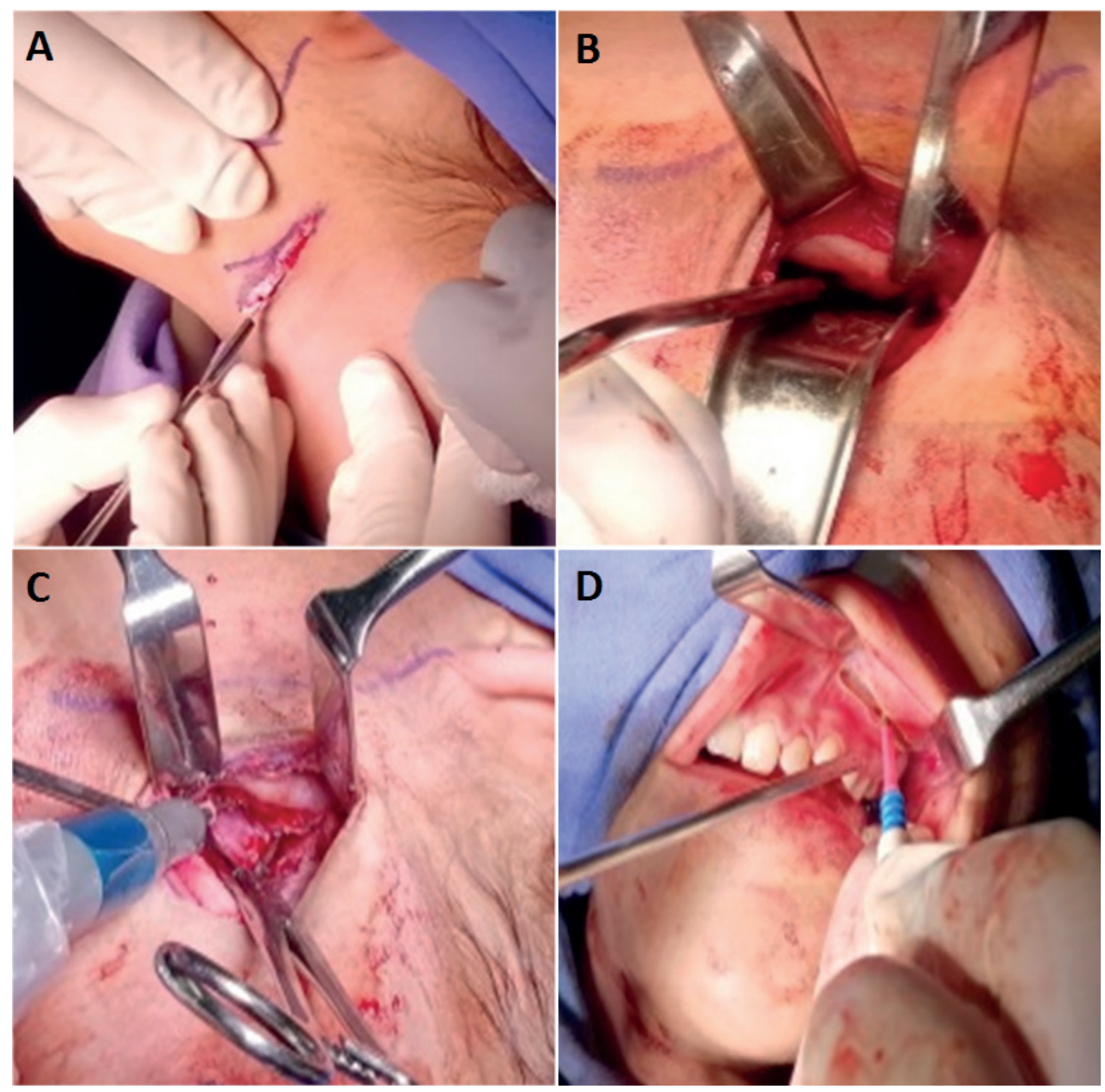

Figura 5. A-B. Abordaje extraoral. C-D. Intraoral 


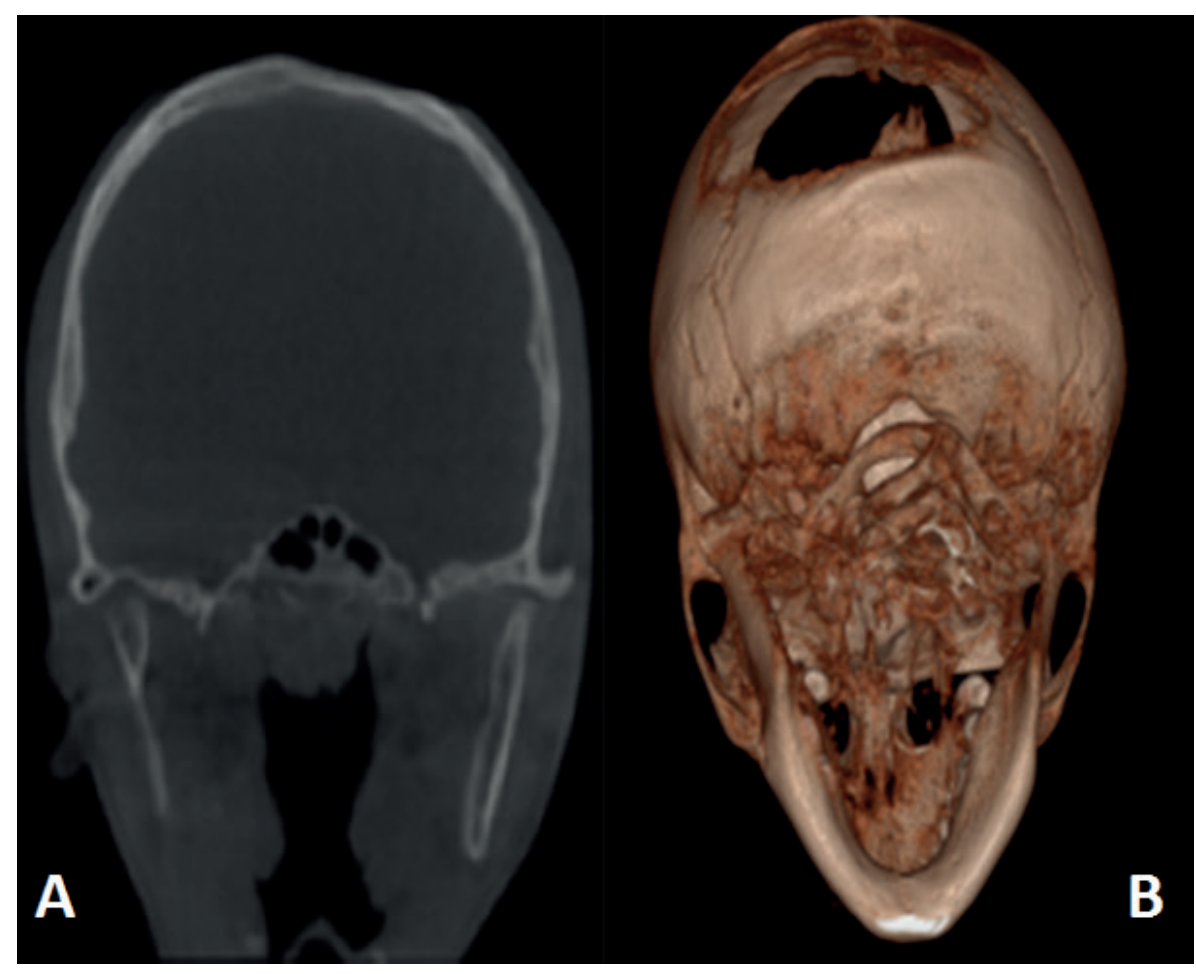

Figura 6. A. Proyección tomográfica coronal: ausencia de calcificación. B. Reconstrucción 3D confirma hallazgos

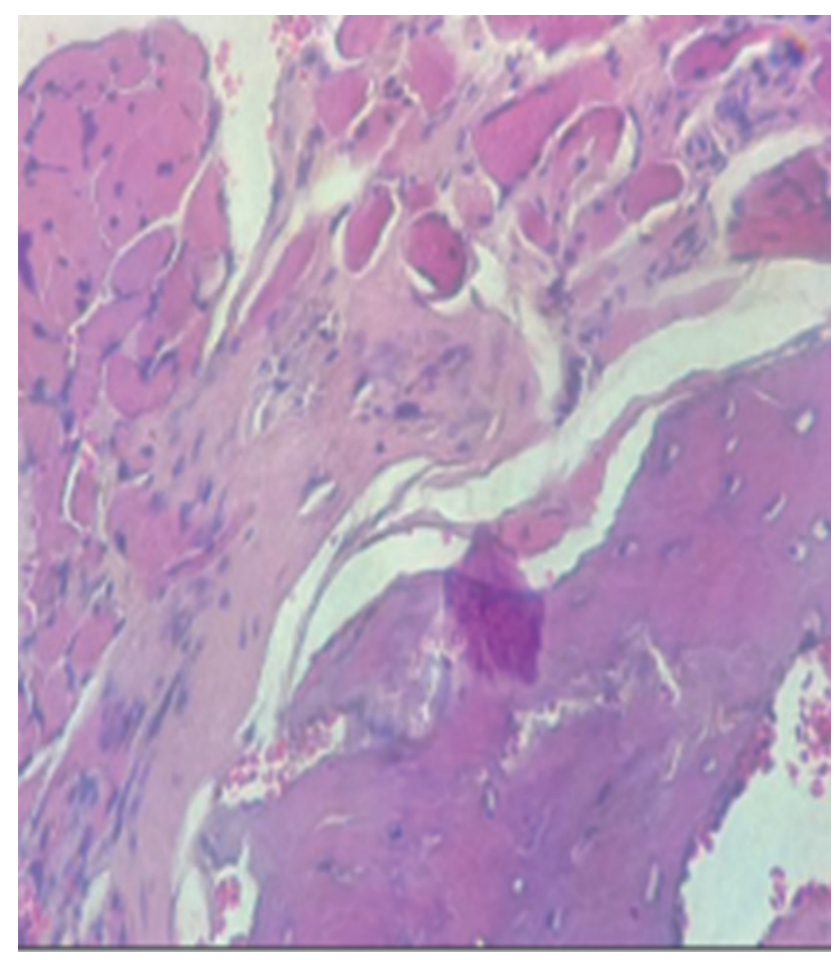

Figura 7. Espécimen patológico

recuperación de una lesión. En la región maxilofacial este trauma puede ser la extracción dental, la inyección de anestésicos, procesos infecciosos crónicos o procedimientos quirúrgicos donde se involucra el músculo ${ }^{23}$. En el caso que reportamos consideramos la administración de la anestesia local durante el procedimiento de la enucleación su principal factor de riesgo, dado que no fueron reportados otros traumas o procesos infecciosos a este nivel, además el quiste dentígero per se, no ha sido considerado como un factor de riesgo dado que se requiere un compromiso específico sobre el músculo y esta lesión se define como la presencia de una cavidad entre el epitelio del esmalte y el esmalte de la corona de un diente en proceso de erupción ${ }^{24}$. 


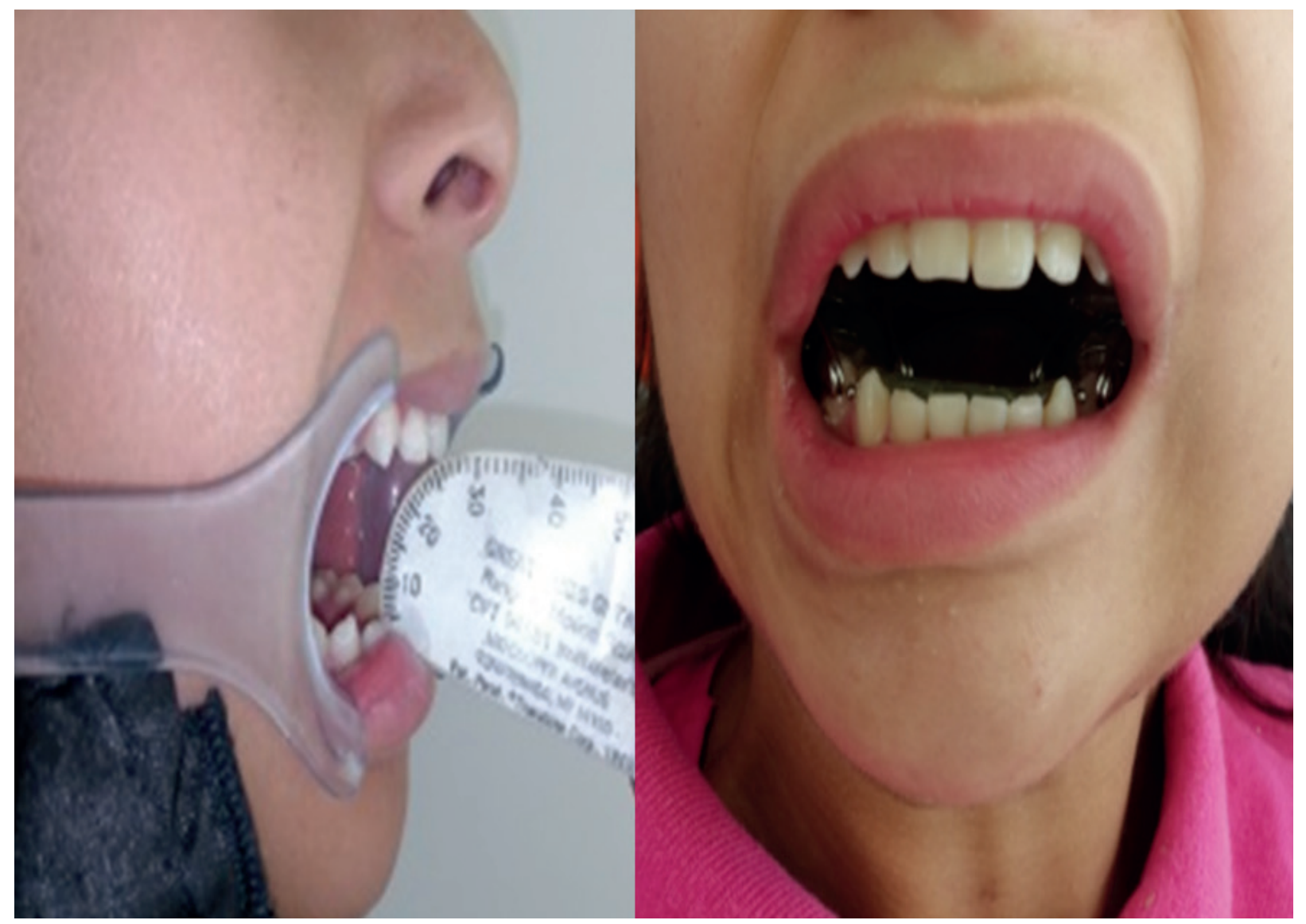

Figura 8. Evaluación postquirúrgica 4 semanas

Generalmente su inicio es asintomático y los pacientes consultan por limitación progresiva de la apertura oral asociado a trismus, como se vio en la paciente de nuestro caso clínico.

No existen estrategias para prevenir la MOT. Una vez que se ha producido una lesión predisponente, la escisión quirúrgica es el tratamiento de elección, en los casos de involucro maxilofacial, con resección completa del tejido calcificado, sin embargo en los reportes de casos no se establece el tipo de abordaje que se debe realizar, ni existe una técnica estándar descrita para su tratamiento, por tal razón nosotros tomamos como referencia el abordaje circunvestibular e intraoral basados en la técnica de abordaje transmaxilar segmentado ${ }^{25}$. El procedimiento debe realizarse cuando ya se encuentra establecido el cuadro, aproximadamente entre la sexta y la doceava semana de inicio de los síntomas ya que si se hace antes de esto se corre el riesgo de desarrollo de nuevo osificación, con mayor extensión de la misma ${ }^{24}$. El pronóstico es generalmente bueno ${ }^{26,27}$, aunque algunas lesiones pueden recurrir, por lo que siempre es recomendado el seguimiento estrecho de estos pacientes para la detección oportuna de recidivas espontaneas de las lesiones.

La literatura ha reportado informes contradictorios acerca de las recurrencias. Kim et al. ${ }^{27}$ informó que, de los 29 casos observados, 14 con seguimiento mayor a un año se presentó recurrencia en el 43\%. Por el contrario Arima et al..$^{26}$ informa 6 recurrencias en 25 casos revisados y Aoki et al. ${ }^{28}$, mostró solo tres recurrencias de 23 casos evaluados. Para estos casos, se han utilizado estrategias no quirúrgicas de tratamiento dentro de las que se destaca la radioterapia, uso de bifosfonatos y antiinflamatorios esteroideos ninguno de ellos con estudios sólidos para su recomendación ${ }^{29}$.

En el caso presentado se optó por el tratamiento quirúrgico dado que era el primer evento de la paciente, en edad temprana, con un factor de riesgo probable, considerándose como abordaje la técnica previamente descrita en dos tiempos para minimizar las alteraciones estéticas dando como resultado una adecuada conservación funcional, sabemos que no es un abordaje estándar, pero en el momento del estudio del caso no encontramos información que estableciera el mismo por lo que al discutir ampliamente las opciones, el presentado fue el que decidimos podría obtener mejores resultados. Al momento de este reporte la paciente se encuentra con apoyo de fisioterapia, sin datos de recurrencia temprana.

Con todo lo anterior concluimos que este es el primer caso de miositis osificante traumática con involucro del músculo pterigoideo medial descrito en México. Se trató con escisión quirúrgica basado en casos publicados en la literatura mundial, y posterior fisioterapia para rehabilitación. Es importante su descripción por el poco 
conocimiento que se tiene de la enfermedad y los excelentes resultados obtenidos, comprender esta entidad, su etiología y fisiopatología puede evitar que se realicen estudios innecesarios y la ansiedad del paciente.

\section{Referencias bibliográficas}

1. Trautmann F, Moura PD, Fernandes TL, Gondak RO, Castilho JC, Filho EM. Myositis ossificans traumatica of the medial pterygoid muscle: a case report. J Oral Sci. 2010;52(3):485-9. DOI: 10.2334/josnusd.52.485.

2. Arima R, Shiba R, Hayashi T. Traumatic myositis ossificans in masseter muscle. J Oral Maxillofac Surg. 1984;42:521-6.

3. Micheli A, Trapani S, Brizzi I, Campanacci D, Resti M, de Martino M. Myositis ossificans circumscripta: A pediatric case and review of the literature. Eur J Pediatr. 2009;168(5):523-9. DOI: 10.1007/s00431-008-0906-8.

4. Boffano P, Zavattero E, Bosco G, Berrone S. Myositis ossificans of the left medial ptery-goid muscle: case report and review of the literature of myositis ossificans of mas-ticatory muscles. Cranimaxillofac Trauma Reconstr. 2014;7(1):43-50. DOI:10.1055/s-0033-1356760.

5. Nilner M, Petersson A. Mandibular limitation due to enlarged pterygoid process and calcification of the medial pterygoid muscle. A case report. Cranio. 1989;7(3):2304. DOI: 10.1080/08869634.1989.11678289.

6. Ramieri V, Bianca C, Arangio P, Cascone P. Myositis ossificans of the medial pterygoid muscle. J Craniofac Surg. 2010;21(4):1202-1204. DOI: 10.1097/ SCS.0b013e3181e17cfa.

7. Wiggins RL, Thurber D, Abromovitch K, Bouquot J, Vigneswaran N. Myositis ossificans circumscripta of the bucinator muscle: first report of a rare complication of mandibular third molar extraction. J Oral Maxillofac Surg. 2008;66(9):1959-1963. DOI: 10.1016/j. joms.2008.01.066

8. Reddy SP, Prakash AP, Keerthi M, Rao BJ. Myositis ossificans traumatica of temporalis and medial pterygoid muscle. J Oral Maxillofac Pathol. 2014;18(2):271-5. DOI:10.4103/0973-029X.140781.

9. Karaali S, Emekli U. Myositis Ossificans Traumatica of the Medial Pterygoid Muscle after Third Molar Tooth Extraction: A Case Report and Review of Literature. J Oral Maxillofac Surg. 2018;76(11):2284.e1-2284.e5. DOI:10.1016/j.joms.2018.06.174.

10. Narang R, Dixon RA. Myositis ossificans: Medial pterygoid muscle. A case report. Br J Oral Surg. 1974;12(2): 229-34. DOI:10.1016/0007-117x (74)90130-9.

11. Kim DD, Lazow SK, Har-El G, Berger JR. Myositis ossificans traumatica of masticatory musculature: a case report and literature review. J Oral Maxillofac Surg. 2002;60(9):1072-6. DOI: 10.1053/joms.2002.34424

12. Tong KA, Christiansen EL, Heisler W, Hinshaw DB Jr, Hasso AN. Asymptomatic myositis ossificans of the medial Pterygoid muscle: A case report. J Orofac Pain. 1994;8(2):223-6.

13. Takahashi K, Sato K. Myositis ossificans traumatica of the medial pterygoid muscle. J Oral Maxillofac Surg 1999;57:451-6. DOI:10.1016/s0278-2391(99)90289-6.
14. Carey EJ. Multiple bilateral parosteal bone and callous formations of the femur and left innominate bone. Arch Surg. 1924;8:592-603.

15. Kaplan FS, Shore EM, Gupta R, Billings PC, Glaser DL, Pignolo RJ, et al. Immunological features of fibrodysplasia ossificans progressiva and the dysregulated BMP4 pathway. Clin Rev Bone Miner Metab. 2005;3:189-93.

16. Chen D, Zhao M, Mundy GR. Bone morphogenetic proteins. Growth Factors. 2004;22(4):233-41. DOI:10 .1080/08977190412331279890.

17. Jiang Q, Chen MJ, Yang C, Qiu YT, Tian Z, Zhang ZY et al. Post-infectious myositis ossificans in medial, lateral pterygoid muscles: a case report and review of the literature. Oncol Lett. 2015;9(2):920-6. DOI:10.3892/ ol.2014.2710.

18. Baysal T, Baysal O, Sarac K, Elmali N, Kutlu R, Ersoy Y. Cervical myositis ossificans traumatica: a rare location. Eur Radiol 1999;9(4):662-664. DOI:10.1007/ s003300050728.

19. Thangavelu A, Vaidhyanathan A, Narendar R. Myositis ossificans traumatica of the medial pterygoid. Int J Oral Maxillofac Surg. 2011;40(5):545-9. DOI:10.1016/j. ijom.2010.10.024.

20. Parkash H, Goyal M. Myositis ossificans of medial pterygoid muscle. A cause for temporomandibular joint ankylosis. Oral Surg Oral Med Oral Pathol. 1992;73(1):278. DOI: 10.1016/0030-4220(92)90149-k.

21. Torres AM, Nardis AC, da Silva RA, Savioli C. Myositis ossificans traumatica of the medial pterygoid muscle following a third molar extraction. Int J Oral Maxillofac Surg. 2015;44(4):488-90. DOI:10.1016/j. ijom.2014.11.003.

22. Hanisch M, Hanisch L, Fröhlich LF, Werkmeister R, Bohner L, Kleinheinz J. Myositis ossificans traumatica of the masticatory muscle: etiology, diagnosis and treatment. Head Face Med. 2018;14:23. DOI: 10.1186/ s13005-018-0180-6.

23. Rattan V, Rai S, Vaiphei K. Use of buccal pad of fat to prevent heterotopic bone formation after excision of miositis ossificans of medial pterygoid muscle. J Oral Maxillofac Surg. 2008;66(7):1518-22. DOI:10.1016/j. joms.2007.05.020.

24. Shirkhoda A, Armin AR, Bis KG, Makris J, Irwin RB, Shetty AN. MR imaging of myositis ossificans: Variable patterns at different stages. J Magn Reson Imaging. 1995;5(3):287-92. DOI: 10.1002/jmri.1880050312.

25. Patel CR, Wang EW, Fernandez-Miranda JC, Gardner P, Snyderman CH. Contralateral Transmaxillary Corridor: AnAugmented EndoscopicApproach to the Petrous Apex. J Neurosurg. 2018;129(1):211-219. DOI: 10.3171/2017.4.JNS162483.

26. Arima R, Shiba R, Hayashi T. Traumatic myositis ossificans in masseter muscle. J Oral Maxillofac Surg. 1984; 42(8):512-6. DOI: 10.1016/02782391(84)90011-9.

27. Kim DD, Lazow SK, Har-El G, Berger JR. Myositis ossificans traumatica of masticatory musculature: a case report and literature review. J Oral Maxillofac Surg. 2002;60(9):1072-6. DOI: 10.1053/joms.2002.34424. 
28. Aoki T, Naito H, Ota Y, Shiiki K. Myositis ossificans traumatica of the masticatory muscles: Review of the literature and report of a case. J Oral Maxillofac Surg 2002;60(9):1083-8. DOI: 10.1053/joms.2002.34427.
29. Soldic Z, Murgic J, Radic J, Dabelić N, Jazvić M, Brozić JM et al. Radiation therapy in treatment of fibrodysplasia ossificans progressiva: a case report and review of the literature. Coll Antropol. 2011;35(2):611-14. 
